\title{
La lingüisticidad de la comprensión como experiencia de diversidad cultural
}

\author{
The Linguisticity of Understanding as an Experience \\ of Cultural Diversity
}

\author{
Carlos Emilio Gende
}

Universidad Nacional del Comahue

\begin{abstract}
RESUMEN: Es habitual caracterizar y evaluar consecuencias de la diversidad cultural tomando como dato las diferencias entre lenguas. $\mathrm{Al}$ respecto, me propongo evaluar los alcances y límites de la relación entre ambas a partir de un examen del tipo de concepción que elabora la Lingüística, que entiende a la lengua como sistema, para contraponerlo a un enfoque hermenéutico, que destaca la lingüisticidad de la comprensión como proceso y no como producto. Respecto de esto último, se ilustrará con la experiencia del diálogo, según Gadamer, y de la traducción, según Ricoeur.
\end{abstract}

ABSTRACT: It is customary to characterize and evaluate the consequences of cultural diversity by taking as a datum the differences between languages. In this regard, I intend to evaluate the scope and limits of the relationship between both, based on an examination of the type of conception that Linguistics elaborates, which understands the language as a system, to counterpose it to a hermeneutic approach, which emphasizes the linguistic of understanding as a process and not as a product. Regarding the latter, it will be illustrated with the experience of dialogue, according to Gadamer, and of translation, according to Ricoeur.

Palabras Clave: diversidad cultural, lenguaje, hermenéutica, diálogo, traducción. KeYwords: cultural diversity, language, hermeneutics, dialogue, translation. ReCiBIDO: 14 de marzo de 2017 • AcEPTADO: 1 de septiembre de 2017 



\section{Carlos Emilio Gende}

Universidad Nacional del Comahue

\section{La lingüisticidad de la comprensión como experiencia de diversidad cultural ${ }^{1}$}

\section{¿Qué hacer con la diversidad?}

Ante la experiencia de la diversidad cultural siempre podríamos actuar como lo hicieron los antiguos: constatarla para después ignorarla. Como sabemos, y Zigmunt Bauman se encarga de recordárnoslo, el conocimiento de la diversidad de culturas, costumbres, lenguas, etcétera, fue un tópico del mayor interés desde siempre; ${ }^{2}$ sin embargo, agrego, no por eso ha sido teorizado como asunto que mereciera ser indagado en su especificidad para extraer consecuencias que pudieran incidir en nuestros modelos explicativos.

Agradezco a los evaluadores de mi propuesta; gracias a su recepción me vi llevado a explicitarla.

2 "Filosóficamente, la reconciliación entre las premisas de los parámetros preformados de la verdad, la belleza y la justicia moral, por un lado, y la variabilidad de estilos de vida aceptados por pueblos diversos, por el otro, debió de producir obstáculos insuperables. No obstante, parece que los griegos nunca llegaron a abordar la cuestión desde un punto de vista teorético: clasificar indiscriminadamente las diferencias explícitas como curiosidades foráneas se puede contemplar como una forma de rodear el problema más que de intentar solucionarlo [...] Toparse con diferencias culturales no quiere decir forzosamente que se perciban como tales; y percibirlas no implica conferir automáticamente un estatus existencial equivalente a los diversos estilos de vida contradictorios" (Bauman 1999: 119). 
Esto seguramente obedecía tan sólo a que no se lo detectaba como problema, pues prevaleció sin más una tendencia a la universalización de los patrones cognitivos. Tal vez, y bien podría ser el trasfondo de cierto tipo de universalización, de ese modo sólo proyecta una singularidad que generaliza por la fuerza $-\mathrm{y}$ así produce lo universal artificialmente- - Puede imputarse esto a factores más ligados a una evaluación política de la diversidad, que permitió subestimar lo distinto como poco valioso, atribuyéndole inferioridad, o bajo una subvaloración enmascarada en pasión por lo exótico o afán de curiosidad. Claro, si el acercamiento a otros grupos humanos sigue una secuencia que inicia con las armas, continúa con el bautismo y termina con la observación neutral, participativa, o como luego se la llame por parte de científicos antropólogos, es esperable el resultado de esa relación con los otros.

De todos modos, no cabe ser peyorativo con estos últimos, pues independientemente de cuáles hayan sido las circunstancias político-sociales que les permitieron acceder al trato con otros grupos humanos, es cierto que mucho les debemos en términos de plantear seriamente a la filosofía y a las ciencias problemas teóricos que surgen de constatar lo diverso. Es decir, aún abroquelados bajo parámetros de interpretación restrictivos que tendieron a sobrevalorar el modo occidental como el que mejor define a lo humano, pareciera que, ante la fuerza de los hechos (para el caso: distintos modos de hablar, religarse, convivir, distribuir el poder, establecer relaciones parentales, etcétera), estos científicos sociales se las debieron ver con experiencias no fácilmente subsumibles en teorías especulativas y apriorísticas sobre las comunidades y su específica humanidad.

Podría hablarse de una suerte de paradoja en todo esto: cuando se desestimaba la importancia teórica de lo diverso fue debido a que los grupos dominantes se atribuían a sí mismos el poder de ejercerlo sobre otros, bajo la excusa de considerarse mejores (salvo excepciones, en que la convivencia lo supo aprovechar para enriquecimiento mutuo). En cambio, cuando la experiencia de la diversidad presiona hasta el punto de convertirse en un asunto necesitado de explicación teórica, es cuando ya no hay modo de desestimarla y no puede obrar como excusa para ejercer el poder de unos grupos sobre otros. Sin embargo, en ese momento, en ese preciso momento en que ya no puede evitarse una 
ponderación positiva de lo diverso, vuelve a necesitarse de algún tipo de universalización que impida la indiferencia típica de una actitud social que ante lo diverso prefiere declararse cínicamente imposibilitada de comprometerse con lo común de lo humano.

Considero que aún nos encontramos en esa ambivalencia: es inadmisible en el plano conceptual que las diferencias entre grupos humanos, por más profundas que sean, puedan explicarse bajo categorías de superioridad e inferioridad; ni por parte de aquellos que suelen atribuirse la superioridad, ni para adjudicársela a los grupos que venían siendo subestimados. Como sostiene el antropólogo Miguel Alberto Bartolomé: "podrá ser un lugar común decir que la diferencia no implica desigualdad, pero sigue resultando un concepto muy difícil de ser comprendido y suele ser disfrazada por más de una formulación teórica que velada o implícitamente pretende negarlo" (Bartolomé, prólogo a Reynoso 2014: 17).

Sin embargo, tampoco sabemos bien qué hacer con esas diferencias, más allá de registrarlas y emplearlas como insumo para revisar una y otra vez nuestras consideraciones sobre la especie humana. Quiero decir, no sabemos bien qué hacer, en términos de qué lugar darle para extraer alguna consecuencia valiosa, si es que la hay, sobre lo que somos. Pues lo que ha solido extraerse es la consecuencia desoladora de la supuesta incomunicación radical a partir de las diferencias infranqueables entre culturas.

Y el dato para eso, tal vez el más abstracto, pero de una concreción pasmosa, dada su condición de intercambio audible - también legible - , ha sido y continúa siendo el de las variaciones entre lenguas. Así, en efecto, el lenguaje - ya veremos qué de él - se eleva a condición, a partir de la cual se evalúan todas las posibilidades de entendimiento de lo que producen y transmiten las culturas como experiencias distintas de la vida. Mejor dicho, posibilidades de mal entendimiento, pues se ha vuelto un lugar común que, en principio, los límites de nuestra lengua son los límites de nuestro mundo, y que a partir de eso poco puede esperarse de una relación lingüística con hablantes de otros idiomas.

El tema que me ocupará a partir de ahora, entonces, es revisar cuál es la caracterización de lenguaje desde la cual se puede sostener semejante sobredeterminación de la experiencia humana — la cual ha llevado a 
adoptar posiciones extremas sobre la diversidad cultural - y si acaso puede ofrecerse alguna caracterización alternativa que no vea en ello un problema a resolver sino una condición propia de lo humano.

\section{La diversidad cultural subsumida en el lenguaje, como sistema de la lengua}

Como es sabido - y de ahí mis alusiones a los antropólogos - los científicos sociales, que ante todo habrían iniciado el tipo de caracterizaciones relativistas y autocentradas de las lenguas, han sido en el siglo pasado los antropólogos; Franz Boas, entre ellos. Consta, por cierto, el antecedente en Alemania de los estudios lingüísticos de Humboldt, pero no es tan lineal la filiación teórica que habrían heredado aquellos y sus postulados ameritan un estudio por separado. ${ }^{3}$

Ahora bien, en relación con esa disciplina podría resultar un tanto extraño que ante la proliferación de vestimentas (incluida la falta de ella), relaciones parentales, diseño de viviendas, danzas, comidas, rituales, relaciones de poder $-\mathrm{y}$ la lista sigue - , se haya tomado a la lengua como dato duro a partir del cual revisar las otras. Señalo esto porque sobre cualquier otra variación siempre podríamos intentar una explicación que dé cuenta del campo motivacional que la produjo, en cambio, sobre la lengua, al menos desde De Saussure, no. Es como si respecto de cualquier otra diferencia estuviéramos habilitados a avanzar teóricamente para así ubicarla en alguna casilla que debilite el efecto de extrañeza, porque establecemos a qué responde, o emergente de qué estructuración simbólica resulta ser un caso (de hecho, buena parte de las disputas internas a la disciplina consisten en lo que proponen como marco teórico: funcionalismo, estructuralismo, marxismo). Pero basta el simple oír hablar sonidos que en principio ni siquiera logramos seg-

Como sostiene Reynoso: "entre las ideas de Humboldt y el posterior relativismo hay una diferencia esencial, pues para aquél las visiones del mundo cristalizadas en el lenguaje son el resultado natural de las formas, potencialmente infinitas, en las que la competencia universal moldea la sustancia de la experiencia individual. La competencia universal referida por Humboldt lo es verdaderamente: las reglas y las formas de significado de las que cada idioma deriva su carácter individual [...] muestra por lo general un principio unitario común" (Reynoso 2014: 66). 
mentar en sus unidades diferenciales, para que el límite en la relación humana se vuelva, en apariencia, infranqueable.

Así y todo, el caso es que, si se acepta esa diferencia radical del sistema de la lengua respecto a cualquier otro, es decir, si se admite que la misma consiste en su constitución arbitraria, inmotivada, es difícil entender por qué se ha llegado a emplearlo como recurso para evaluar supuestos condicionamientos, limitaciones o restricciones sobre nuestra comprensión en general y de las otras culturas en particular. ${ }^{4}$

Es cierto que la arbitrariedad está en el acople de significante y significado, y es ahí donde se exhibe la carencia de razones, motivos y/o causas. Es cierto, también, que eso obedece a que ante el intento de representar cada uno de los sistemas por separado nos hallamos ante dos masas amorfas, es decir, no podemos representarnos nada como contenido significativo aislable, vehiculizado a su vez mediante una forma preestablecida. Sin embargo, examinado todo esto desde dentro de cada una de las lenguas, que es lo que siempre nos ocurre, nos hallamos ante una totalidad fuertemente organizada y estable, la cual, sin haber sido elegida por nosotros, obra no obstante como condición para todo lo expresable. Y cada lengua lo hace a su modo, sin razones ni motivos que justifiquen el enlace, pero con una eficacia que nos hace olvidar cuán arbitraria ha sido su constitución.

Así, una descripción cualesquiera de la diversidad de fenómenos socioculturales, pero inmanente a la lengua entendida como sistema, siempre puede ser empleada para encorsetar la experiencia, pues al subsumirla en un modelo hipercodificado cuyas reglas no se extraen del campo motivacional de la vida social que expresa, sino, al contrario, se le impone para explicarlo, predispone, como si de una ilusión óptica se tratase, a extraer lo pensable de lo decible, apoyándose ante todo en que este último es el único dato certero y tangible en el que basarnos.

Por cierto, ya se cuenta con abundante desarrollo teórico como para desestimar las posiciones relativistas extremas basadas en las diferen-

\footnotetext{
$4 \quad$ Sobre todo, si, como sostiene Norbert Elías (1989: 111): "la cuestión de cómo la red de símbolos de un idioma llega a surgir de formas de comunicación prelingüísticas más animales entre antepasados de los grupos humanos actuales y de cómo se convirtió en un gran número de idiomas diferentes constituye la frontera actual del conocimiento humano".
} 
cias entre lenguas, quedando algunas de ellas, incluso, deslegitimadas como fábulas. ${ }^{5}$ Sin embargo, tal vez porque tampoco son satisfactorias las teorías que universalizan sin más, sobre todo cuando para ello desatienden la contribución conceptual que proviene de detectar lo específico de las variaciones, y tal vez, en el fondo, porque sigue siendo demasiado sugerente tomar al dato incontestable de la diversidad de lenguas (aunque no se haya logrado justificar la relación causal con la diversidad cultural ni con las competencias cognitivas), es que vemos de tanto en tanto aparecer versiones más o menos sofisticadas que la siguen defendiendo.

En efecto, tanto la búsqueda de universales lingüísticos, como la defensa de los particularismos irreductibles, son objeto de controversia, independientemente de su aplicación para la diversidad cultural. $\mathrm{Al}$ respecto, o bien las investigaciones se orientan a la postulación de un universal abstracto, para lo cual, de acuerdo con Duranti (1997), los investigadores nunca asumen la ardua tarea de contrastar con las prácticas lingüísticas efectivas, o bien, se les contrapone un estudio empírico de casos - tarea afín al mismo Duranti-, que, a mi juicio, es insuficiente para mostrar la improductividad del primero. Sospecho que esto se debe a que sus resultados terminan resolviéndose por la vía del absurdo, si es que nos interrogamos por la diversidad lingüística: o bien la abstracción operada en la lengua se declara irrealizada de hecho, por ende, inexistente; o bien la constatación de ejemplos de uso se vuelve tan local, singularizada y circunscripta al momento, que se pierde de vista la relación con el sistema, del que es emergente, ocasión de cambio o realización. En la primera, al preservarse el sistema se cree poder desechar el caso "anómalo", porque se identifica como tal; en la segunda se cree poder exacerbar el dato - como muestra incomparable de lo singular-, pero perdiendo de vista acerca de qué es esa singularidad.

A su vez, es recurrente que en el segundo caso se abuse de descripciones sociológicas y psicológicas, que no siempre advierten que

En 1983 el lingüista Ekkerhart Malotki escribió El tiempo en la lengua Hopi como resultado de un trabajo de campo. Allí describe las numerosas expresiones sobre el tiempo que aparecen en esta lengua, así como el sistema y el aspecto temporal de lo que Whorf había considerado "verbos sin tiempo". De ese modo, ofrece una refutación decisiva de la principal tesis de este último (Deutscher 2010: 160). 
de ese modo tal vez no estén analizando la lengua, sino aquello que suponen modo de vehiculización de otra cosa: diversidad social y/o psicológica.

Al menos Sapir, en su etapa anterior a la relación con Whorf, adoptó la estrategia de distinguir forma y contenido en la lengua, a partir de lo cual sostuvo que si bien es cierto que desde el punto de vista del contenido hablado - del aspecto lexicológico-, puede mostrarse cuán relacionada está la lengua con la cultura en que se habla - con los modos de vida - ; desde el punto de vista de su estructura, la lengua es totalmente independiente del supuesto temperamento de una cultura, e incluso, sostiene, del aspecto emotivo de la vida psíquica que, según él, influye muy poco en la configuración del lenguaje. Cabe consignar, por otra parte, que es este aspecto estructural el que le interesa indagar al autor (Sapir 2010: 246-247), asunto que destaco porque se trata de alguien a quien se lo considera referente del relativismo lingüístico.

En este sentido, no es fácil y tal vez sea infructuoso como programa de investigación, defender una caracterización del lenguaje como vehículo de contenidos - la teoría instrumentalista del lenguaje-, aunque también es difícil defender la determinación del pensamiento por la lengua, pues, en el mejor de los casos, lo que podría mostrarse es una retroalimentación, aunque para ello hay que aceptar la relación entre dos planos en principio distinguibles: el de la formación de los vocabularios y el de los conceptos. Así y todo, tampoco sabríamos cuál dimensión destacar para la formación: si acaso semántica, sintáctica y/o pragmática. Y aún si así fuera, quedaría por resolver cuánto de universalizable hay en esas dimensiones, además de evaluar qué importancia pudiera tener para una descripción compleja y madura de aquello que entendemos por lenguaje.

Es cierto también que para su descripción no debiéramos confundir distintas categorías de análisis. De ese modo, insisto, bien puede aclararse que el universalismo suele destacar el plano de la lengua, mientras que los particularismos proponen reconocer "repertorios", "comunidades lingüísticas", "modos de uso" y otros conceptos especialmente diseñados. Así, la especificidad de empleos, según grupos sociales, estratificaciones etarias, profesiones, técnicas, procesos de censura social, estigmatización sexual, etcétera, etcétera; hasta llegar a lo que 
con Bajtin se llamó "heteroglosia", puede volver metodológicamente imposible una investigación que quisiera reconocer la diversidad de prácticas lingüísticas, aún en una sociedad y en un tiempo presente.

Esto, en el mejor de los casos, muestra que habría al menos dos modos interesantes de abordar la diversidad linguística: la que asume las diferencias radicales entre las lenguas, como sistemas más o menos reconocibles por fuera de su situación de empleo; y la que detecta las diferencias profundas internas en un mismo sistema de la lengua. Sin embargo, ambas ponen entre paréntesis la pregunta sobre la diversidad. La rescatan, la defienden, incluso la promueven; pero cuando se indaga en sus respectivas razones, aparece de inmediato la imposibilidad de establecer una genealogía que agote la explicación de las profundas diferencias entre los sistemas lingüísticos; y es entonces Babel el recurso mítico que, si bien no explica, al menos relata. ${ }^{6}$

\section{Descripciones contemporáneas de la relación lenguaje y cultura: Everett y Deutscher como lingüistas}

Claro, al uso de los tiempos, el intento ahora es mostrar que hemos vivido equivocados y que son otros pueblos, precisamente los antes subestimados, de los que deberíamos aprender a relacionarnos con el mundo y con los otros, para lo cual se emplea como insumo la experiencia de diversidad lingüística. El caso de Daniel Everett y su famoso libro No duermas, hay serpientes. Vida y lenguaje en la Amazonia, es quizá el mejor ejemplo contemporáneo. Su estrategia discursiva es de lo más convincente, pues divide el texto en dos apartados bien diferenciados: vida y lenguaje. En el primero muestra lo absolutamente "otro" en el modo de vida de los Pirahá y lo fascinante y complejo que le ha resultado entrar en relación con ellos como pastor protestante, cuyo objetivo inicial era traducirles la Biblia, hasta llegar a una situación de profunda conversión existencial en que deja a su esposa, religión y ambiciones académicas para convertirse en un difusor de las virtudes del modo de vida de aquel grupo. Luego, en la segunda parte del libro, describe el

6 Desarrollo este tema en Gende (2013: 51-52). 
sistema de esa lengua, a partir de lo cual, otra vez, la pretensión de que "lo otro" es lo absolutamente otro se potencia y se explica, finalmente, por el funcionamiento de esa lengua. Su estrategia es especialmente sugerente, pues él mismo se ubica de entrada en lo que se denomina etnogramática (Everett 2008: 264), según lo cual insiste una y otra vez en que la lengua está moldeada por la cultura.

No obstante, pasa sin mayor justificación a analizar, hacia la mitad de esta segunda parte de su libro, el sistema de la lengua Pirahá como tal, para extraer consecuencias de lo que no puede entenderse de otro modo que como limitaciones cognitivas en la mentalidad de ese grupo. Esa lengua, según sus informes, carece de recursividad, nombres para colores, nombres para relaciones parentales, incluso para hacer operaciones matemáticas simples como la suma. A esto se agrega que, según sostiene, no relatan mitos de la creación o de su origen (Everett 2008: caps. XIII-XVI).

Para una crítica detallada de los procedimientos metodológicos, tanto lingüísticos como antropológicos - mejor dicho, de su carencia-, que habrían llevado a Everett a semejantes conclusiones y que aluden a una teoría del déficit cultural, remito a Lenguaje y pensamiento, reciente obra del antropólogo Carlos Reynoso, en el cual evalúa el conjunto de su obra destacando las inconsistencias. En esta ocasión me interesa señalar que en el libro de Everett que comento, el autor, ante todo, apela al principio de "inmediatez de la experiencia" para explicar buena parte de las carencias cognitivas que se consolidarían en el sistema de la lengua (Everett 2008); no obstante, este último pasa de ser modelo privilegiado de registro de aquella, a principio causal de las diferencias culturales. Lo curioso es que no ofrece pruebas de lo uno ni de lo otro.

Una versión, también inmanente a la lengua como sistema, pero superadora de las restricciones que inevitablemente conducen al relativismo extremo de Everett, es la de Guy Deutscher en El prisma de los colores. Allí, luego de desandar la historia de cómo se teorizó acerca de la diversidad en la percepción y/o denominación de los colores, arriba a una explicación que él reconoce provocadora para los estándares contemporáneos, pero que, sin embargo, permite atender tanto al modelo de determinación lingüística como a mostrar sus alcances y límites. Precisamente se trata de establecer en qué sentido la lengua es una 
condición límite, pero que por eso mismo es ocasión para la apertura y modificación de la experiencia lingüísticamente moldeada. Así, propone reemplazar la hipótesis Sapir-Whorf por la hipótesis Boas-Jakobson. Según Deutscher, este último condensó la intuición de Boas respecto a que además de determinar la relación entre las palabras de cualquier frase, la gramática tiene que "determinar los aspectos de cada experiencia que deben ser expresados" (Deutscher 2010: 168), aspectos que varían considerablemente de una lengua a otra. Jakobson lo reformula así: "las lenguas difieren básicamente en lo que deben transmitir, no en lo que pueden transmitir" (Deutscher 2010: 168). Parece una sutileza, pero no es lo mismo sostener que las lenguas restringen lo pensable a partir de lo decible desde su sistema, a sostener que si bien las lenguas compelen a expresar en el decir determinada información desde su estructura, eso no impide agregarle otra, o incluso modificarla por ampliación. Deutscher extrae de esto que si "la lengua obliga a sus hablantes a prestar atención a ciertos aspectos del mundo cada vez que abren la boca o aguzan los oídos, esos hábitos del habla pueden posiblemente convertirse en hábitos mentales con consecuencias sobre la memoria o sobre la percepción o las asociaciones o incluso las habilidades prácticas" (Deutscher 2010: 179), para lo cual ofrece suficientes ejemplos obtenidos de la psicología experimental (Deutscher 2010: caps. VII-IX). Sin embargo, insiste, y sigue en ello una línea que remite a Humboldt: "en teoría cualquier lengua puede expresar cualquier asunto" (Deutscher 2010: 179).

\section{Lenguaje y cultura: relación sin subsunción desde la Hermenéutica}

Ahora bien, si así son las cosas, si aún a partir del efecto de predisposición que la lengua ejercería sobre lo pensable, se puede modificar la estructura misma de la lengua, es, a mi juicio, porque no alcanza con una descripción inmanente al sistema para entender de qué se trata la experiencia lingüística. Adelanto mi respuesta: todo lo descrito hasta ahora ha girado alrededor del producto, no del proceso y, como tal, no logra dar cuenta de los cambios o transformaciones de otro modo que como accidentes del sistema, absorbidos por éste sin mayor justificación que 
la de las reglas internas al mismo. Con ello quiero sugerir que habría que revisar procesos del entendimiento eminentemente lingüísticos, es decir, que no ocurrirían de otro modo más que vía el lenguaje, pero que, a la vez, sólo ocurren asumiendo la integralidad de cada proceso: el diálogo, la escritura, la lectura, la traducción, la enunciación metafórica, son algunos de ellos y en ninguno la diversidad es un problema sino una condición para la comprensión.

Una antropología lingüística como la de Alesandro Duranti, por ejemplo, avanza en uno de estos procesos, el diálogo, como vía privilegiada para describir mejor de qué se trata el intercambio lingüístico. Sin embargo, lo hace a la manera científica, por adición de actividades o situaciones propias de ese intercambio lingüístico. A las ya conocidas, propone, hay que incorporar ahora la ubicación espacial, el tono y volumen de la voz, la gestualidad y el modo de mirar, entre otras. Sugiere que, metodológicamente, se trata más de una atención visual que auditiva la que debe ejercer el estudioso cuando realiza entrevistas presenciales, lo cual es pertinente y muestra un cambio notable en las condiciones que se establecen para constatar la complejidad de una situación comunicativa real, en el sentido en que se aspira a reconocer la mayor cantidad posible de variables que intervienen en ella (Duranti 1997: caps. VII-IX). Al respecto, cabe sospechar si el asunto a indagar: si la diversidad - tanto lingüística como cultural - es constitutiva de lo humano y, en ese sentido, no es un problema a resolver sino una modalidad a explorar, puede acaso tratarse por adición de sistemas que se sobreimponen unos a otros con la pretensión de asir mejor el objeto de estudio. Más aún, la cuestión es si acaso se trata de un objeto de estudio o de una experiencia a tematizar. Si lo primero, lo aconsejable es el trabajo interdisciplinario que procura completar, como tarea infinita, el acceso al objeto. En cambio, si lo que interesa es recuperar una experiencia integral de lo humano en su diversidad, una que a su vez supone la lingüisticidad de la comprensión como situación irrebasable más allá de lo cual no hay condiciones de posibilidad de lo pensable, tal vez haya que intentar - paradójicamente - una experiencia de esa lingüisticidad desde la inconsciencia linguística.

En ese sentido, sugiero que es del campo filosófico hermenéutico, en obras como las de Hans George Gadamer y Paul Ricoeur, del que pode- 
mos obtener una mejor caracterización acerca de cómo proceder, para entender que la diversidad no es un problema a resolver, sino una experiencia de excedente de sentido para aprovechar. Estas obras lo logran porque desde una actitud muy distinta a la de los comentados, tematizan procesos de entendimiento lingüístico sin tomar al sistema de la lengua como dato más allá del cual nada es pensable, sino como actividades orientadas a la comprensión, como acontecimientos de sentido. ${ }^{7}$

En prescindencia de los resultados que la Lingüística como ciencia ofrece, con Gadamer, o, al contrario, como respuesta que asume el desafío de un largo rodeo por sus teorías, con Ricoeur, la atención puesta por ambos en los procesos y no en los productos, habilita a estas hermenéuticas del lenguaje a defender incluso una versión del "giro lingüístico" que muestra su condición irrebasable, sin reducir por ello los asuntos ontológicos y gnoseológicos en la matriz de cada lengua. Así, lo irrebasable no es la formación de cada lengua como estructura, sino el proceder lingüístico de la comprensión que se plasma en actividades como las señaladas.

Gadamer, con su versión del diálogo, invierte precisamente los postulados de la lingüística cuando sostiene que el tema no es cómo cada lengua "está en condiciones de decir todo lo que quiera a pesar de su diversidad respecto de las demás", sino "cómo actúa en todas partes la misma unidad de pensar y hablar dentro de la multiplicidad de estas maneras de hablar, y cómo logra que en principio cualquier tradición pueda ser entendida" (Gadamer 1975: 483).

Tal vez de un modo demasiado radical para el tipo de enfoque lingüístico que prefiere la ciencia, pero con una efectividad descriptiva notable, Gadamer propone como experiencia por antonomasia la inconsciencia linguística, con lo cual apunta a evitar el metalenguaje como modo de indagación acerca de nuestro entendimiento. Y al menos con el caso del diálogo, que en el fondo es el modo de realización privilegiado que subyace a toda su hermenéutica, permite descubrir un proceso

Como es sabido, la noción de acontecimiento de sentido es recuperada por la hermenéutica de Ricoeur en la obra de Emile Benveniste. Con ella se procura una redescripción de la instancia de discurso que evita y supera la polarización estructuralista entre lengua y habla. Así, el acontecimiento de sentido muestra que el acto de habla ya no puede ser dejado de lado como aquello evanescente y accidental, opuesto al carácter permanente y esencial de la lengua. 
lingüístico del entendimiento que avanza o retrocede por el asunto que se constituye a partir de él y desde el cual los hablantes se descubren orientados, y no por la objetivación del aparato lingüístico revisado en abstracción de la situación de empleo.

En efecto, Gadamer dedica un capítulo de su obra mayor, Verdad y método, a recorrer el camino en la "acuñación del concepto de 'lenguaje' a lo largo de la historia del pensamiento occidental", para poner a prueba un esquema interpretativo que va de la inconsciencia a la devaluación lingüística, pasando por la conciencia lingüística. No se trata de un esquema lineal en su despliegue histórico, sino, más bien, de un común proceder en nuestros tratos teóricos con el lenguaje, para lo cual Gadamer detecta distintos momentos en cada uno de los grandes periodos de la historia filosófica en los que puede recuperarse la inconsciencia lingüística, a pesar de la habitual devaluación que se produce en cada toma de conciencia. Y esto porque, a su juicio, "la inconsciencia lingüística no ha dejado de ser la auténtica forma de ser del hablar" (Gadamer 1975: 486).

Por razones de espacio y oportunidad no vamos a seguir su derrotero, pero sí nos interesa retener algunas de las caracterizaciones del lenguaje que permiten justificar esta afirmación. Así, si en la experiencia griega, que se mantuvo en una tensión de admiración y temor por los rendimientos del lenguaje, finalmente se consolida una subsunción de la lingüisticidad en sistema de signos, ${ }^{8}$ será en la experiencia del Medioevo en la cual, sostiene, se "hace más justicia al ser del lenguaje" (Gadamer 1975: 509), debido a que, en su elaboración de un modelo lingüístico para pensar la teología trinitaria, se obtuvo implícitamente un aprovechamiento teórico del problema de la encarnación, que repercutió en una caracterización más elaborada de la formación lingüística

\footnotetext{
En su detallado examen del Cratilo, Gadamer llega a la conclusión de que la devaluación en la experiencia griega se da por la pretensión de investigar el "verdadero ser de las cosas [...] sin los nombres [esto] quiere decir que en el ser propio de las palabras como tales no existe acceso alguno a la verdad, por mucho que cualquier buscar, preguntar, responder, enseñar y distinguir esté obligado a realizarse con los medios lingüísticos. Con esto queda dicho también que el pensamiento llega a eximirse a sí mismo del ser de las palabras — tomándolas como simples signos que dirigen la atención hacia lo designado, la idea, la cosa-, que la palabra queda en una relación totalmente secundaria con la cosa" (Gadamer 1975: 497).
} 
de los conceptos en relación con las cosas: "el misterio de la trinidad encuentra su reflejo en el milagro del lenguaje en cuanto que la palabra, que es verdad porque dice cómo es la cosa, no es ni quiere ser nada por sí misma [...] tiene su ser en su cualidad de hacer patente lo demás" (Gadamer 1975: 505). Ahora bien, lo que resulta de estas indagaciones es una descripción virtuosa del proceso de formación lingüístico que no consiste en el de subsunción del caso en la ley - al modo del sistema legaliforme - , sino en el de la continua expansión de los esquemas conceptuales vía la adecuación a situaciones nuevas de aplicación. Lo que podría haber sido descrito por alguna tradición logicista como relación de lo esencial con lo accidental, Gadamer lo redescribe al modo de un reenvío permanente al sistema, que se ve así obligado a modificarse si no resulta suficiente para albergar la novedad; con la consecuencia, destaca, de "la libertad para una conceptuación infinita y una progresiva penetración en los objetos de referencia" (Gadamer 1975: 513). Se trata de lo que ha dado en llamar "metaforismo fundamental" (Gadamer 1975: 515), del que destaco su productividad para reconocer la experiencia lingüística en expansión, según transposiciones que son fruto de una experiencia particular y no de una conceptuación abstractiva. ${ }^{9}$

Ahora bien, esta tematización del lenguaje que no lo vuelve objeto depende, como señalamos, de trabajar en pos de mantenernos en -o de lograr - la inconsciencia lingüística. Como también afirmamos, esto significaría, por la negativa, no elaborar un metalenguaje, procedimiento usual para las ciencias del lenguaje y gracias a lo cual habrían logrado sus modelos explicativos. Sin embargo, no hay propuesta metodológica alguna en la obra de Gadamer - por la positiva - para conseguir aquello, y esto obedece a la razón simple de que la inconsciencia lingüística describe nuestro normal proceder lingüístico en relación con las cosas y con los otros. En efecto, nuestra relación habitual con las palabras - por tomar una formación típica - no consiste en buscar su significado en el diccionario, sino en darla, ofrecerla al otro como compromiso con lo que afirmo. Tampoco es habitual emitir enunciados - otra formación-, respecto de los cuales hubiera que evaluar su forma lógica para después

9 Prescindo en esta ocasión de su recorrido por la Modernidad, pues ameritaría un artículo exclusivo su tratamiento de Humboldt y, antes que él, su recuperación de Nicolás de Cusa como transición entre épocas. 
procurar un emparejamiento con el estado de cosas que pretende describir, sino que lo común es dialogar con otros sobre asuntos que nos "arrastran", que nos muestran rebasados en nuestro opinar (Gadamer 1992: 181-194). Así, no es que debamos ignorar artificialmente nuestra posición inicial, o modo efectivo en que se nos aparecen las cosas según nuestra subjetividad; al contrario, no habría otro modo de entrar en diálogo. Pero si hemos logrado transcurrir en él, las perspectivas de los hablantes se relativizan; y no porque se consolidan como puntos de vista o perspectivas, sino porque ambas quedan modificadas según el asunto común dispuesto por el diálogo, que acontece conforme los hablantes se dispongan a hablar de algo y no de sí mismos. ${ }^{10}$

Las consecuencias para tematizar la diversidad son destacables. Ante todo porque se trata de la manifestación de un modo de ser típico de la humanidad, en que se expresa su relación libre del entorno y, a la vez, se descubre teniendo un mundo: "porque el hombre está capacitado para elevarse siempre por encima de su entorno casual, y porque su hablar hace hablar al mundo, está dada desde el principio su libertad para un ejercicio variado de su capacidad lingüística" (Gadamer 1975: 533). Pero esto, que podría derivar en un perspectivismo de acepciones de mundo, es conducido por Gadamer gracias a su defensa del diálogo en una caracterización productiva de la lingüisticidad de la comprensión, pues lo que ocurre en este proceso es una relación con el mundo orientada por el asunto, el cual, a su vez, sólo queda exhibido por y con el intercambio de preguntas y respuestas que dispone el diálogo.

10 En Gende (2006), objeto las críticas de Cristina Lafont en La razón como lenguaje, quien sostiene que la posición de Gadamer no puede evitar el relativismo típico del giro lingüístico de corte alemán, por el carácter irrebasable otorgado al lenguaje, que volvería irrevisable la configuración del mundo de la vida al que pertenecen los hablantes. Mi evaluación al respecto es que, al contrario, el modelo del diálogo así presentado es condición de la transformación de perspectivas y búsqueda de lo común, que nunca se respalda en una anterioridad del mundo dado, sino en el mundo por venir. Admito que puede reprochársele a esto adoptar cierto estilo de desiderátum; de hecho, el mismo Gadamer ha tenido que salir al cruce de las objeciones de Derrida ante su postulado de una buena voluntad por parte de aquellos que dialogan. Pero también al revés, no es inusual tener la experiencia de haber transcurrido en diálogo; es más, forma parte de nuestra habitualidad en más ocasiones de lo que suponemos. 
En el caso de la obra de Paul Ricoeur, como adelanté, su aporte hermenéutico sobre el lenguaje ocurre como resultado de transitar un largo camino (para tomar prestada su terminología) de asimilación y confrontación con las ciencias del lenguaje, en especial la escuela estructuralista; a diferencia de lo que ocurriría en la obra de Gadamer, quien al igual que su maestro, Heidegger, habría tomado un camino corto para llegar a sus conclusiones. Sospecho que la decisión epistémica de Ricoeur, respecto a no expedirse sobre un asunto sin haber recorrido previamente el discurso de la ciencia, lo lleva a establecer distinciones conceptuales de las que podemos obtener mejores rendimientos para el asunto que nos ocupa. En especial, el desafío de la semiología, con su postulado de inmanencia linguística lo pone en situación de establecer claras diferencias entre oralidad y escritura, entre diálogo y lectura, entre procesos de lingüisticidad de los copresentes ante la situación "cara a cara" y procesos de lingüisticidad de los ausentes, ante la recepción de un texto, debido a la triple ausencia del autor, contexto de producción $\mathrm{y}$ auditorio original.

La descripción del lector como aquel intérprete que se transforma ante el texto, que se refigura en su mundo de lector en un acto de apropiación del mundo desplegado por el texto, para cuyo logro requiere como condición la desapropiación de su voluntad de persistir como intérprete que impone sus claves y deseos, en síntesis, que elige "perderse para encontrarse", sólo se entiende si abandonamos metáforas insuficientes, como la del lector que escucha y/o dialoga con el texto. La tarea del lector, su actividad, realiza un acontecimiento de sentido, que ya no es el de su autor, pero tampoco es el de su satisfacción como receptor más o menos competente que sale a buscar en los textos la confirmación de sus supuestos previos. El texto, desde su silencio, opone resistencias, está configurado como artefacto lingüístico inmanente y estructurado y, a la vez, ha sido elaborado, por lo cual le antecede un mundo prefigurado respecto del cual es una respuesta posible. Pero insisto, no habla, por lo cual impide entrar en diálogo con él y sólo habilita a leerlo. Y en ocasiones la lectura depende de una resistencia previa, tal vez la más radical de todas y que exige entonces una vuelta de sí sobre la lengua: la traducción.

Me interesa, para finalizar, señalar brevemente la presentación de Ricoeur de la actividad traductora, como situación práctica, para cuyo 
examen, si bien retoma sus hallazgos en teoría de la interpretación, repercute especialmente en una reflexión de la lengua sobre sí misma, reflexión producida como resultado de un trabajo. Trabajo que, a su vez, denomina de duelo y de recuerdo, pero trabajo al fin, es decir, punto de llegada provisorio, gracias a la elaboración lingüística que trata con los registros de las lenguas y desde la ambición del traslado (Ricoeur 2004: cap. 1).

Si bien es cierto que, a juicio de Ricoeur, el traductor sufre la tensión entre dos extremos que lo reclaman: el de su propia lengua, con la cual tiende a la identidad totalitaria y que lo lleva a sacralizarla para imponerla a las otras; y el de la lengua del texto que tiene ante sí, que se impone como una resistencia infranqueable ante la que prevalece el fantasma de lo intraducible, no obstante, asume como hecho incontestable que siempre hubo traductores, políglotas, bilingües. Esta constatación tan simple de una práctica lingüística - entre personas que hablan entre sí, a pesar de ser hablantes nativos de lenguas distintas y entre personas y textos que se esfuerzan por verter en su idioma - debería inhabilitar, sugiere, la claudicación ante la lengua del otro, pero también la pretensión idealizada y abstracta de salir a buscar tanto la lengua perfecta como la lengua de origen a partir de las cuales regimentar la diversidad de idiomas.

La traducción es un proceso de realización lingüístico que, por supuesto, trabaja a partir de los productos, es decir, de las lenguas constituidas como tales, pero que, entendida como tarea entre lenguas, desde la actividad de un intérprete que asume el desafío de verter un texto singular en otro, igual, pero distinto, supera la tan mentada incomunicación que sólo en abstracto se presenta como infranqueable. De allí que Ricoeur sostenga que la experiencia de traducir no pugna entre pretensiones de verdad y de error, sino de fidelidad y traición. Y no porque su hermenéutica no esté orientada a satisfacer las pretensiones cognitivas de verdad; al contrario, buena parte de sus esfuerzos teóricos ambicionan expandirlas hasta abarcar procedimientos discursivos que una tradición muy literalista ligada a exigencias empiristas se las han negado; por ejemplo, el enunciado metafórico. Sino porque redescrito el asunto como experiencia lingüística del entendimiento, debe vérselas con lo que de esfuerzo, sufrimiento y frustración conlleva; también de logro y 
satisfacción, por supuesto. Pero es una experiencia de lo provisorio, no de la certeza, y así, entonces, de una tarea inacabable.

\section{A modo de cierre}

Para concluir, estos últimos enfoques nos ofrecen resultados importantes para ver en la diversidad una condición de gran fertilidad heurística y no un problema a resolver. La diversidad lingüística no consiste en una variedad de moldes a partir de los cuales debamos interrogarnos si superarlos vía el universalismo de una lengua abstracta o vía el relativismo de una histórica y socialmente constituida. No hay nada que superar, pues no se trata de un asunto entre sistemas más o menos estructurados, hipo o hipercodificados. La relación, trabajosa, por cierto, a menudo frustrada y en ocasiones gozosa, se da entre personas que hablan entre sí o personas que leen textos. Y en ambos procesos lo que se procura es comprender y comprenderse, ante el texto, ante el otro y en relación con el mundo.

Elegí ilustrar en ambos procesos hermenéuticos lo que exhiben como principios distintivos: la necesidad de inconsciencia lingüística en uno como situación para el diálogo, y al revés, la vuelta reflexiva sobre sí de una lengua, como resultado del acto de traducción de una obra singular. ¿A qué viene presentarlos en estos extremos? Me interesa sugerir que de todos modos, en ambos, la diversidad invita a la formación, a la transformación de las perspectivas, incluso y tal vez en principio, de la misma lengua sobre sí misma. La experiencia lingüística de fondo que se vive desde cada lengua en acto, en cada instancia de discurso, siempre con otros y en relación con el mundo, es la posibilidad de decir — ¿lo mismo? - , siempre, de otro modo.

\section{Bibliografía}

B Auman, Zigmunt (1999). La cultura como praxis. Barcelona, Paidós.

Elias, Norbert (1989). Teoría del símbolo. Un ensayo de antropología cultural. Barcelona, Península. 
Everett, Daniel (2008). No duermas, hay serpientes. Vida y lenguaje en la Amazonia. Madrid, Turner Noema.

Deutscher, Guy (2010). El prisma del lenguaje. Cómo las palabras colorean el mundo. Barcelona, Ariel.

DuRAnTI, Alessandro (1997). Antropología lingüística. Madrid, Cambridge University.

GadAmer, Hans-George (1975). Verdad y método. Salamanca, Sígueme.

- (1992). Verdad y método II. Salamanca, Sígueme.

Gende, Carlos (2005). Lenguaje e interpretación en Paul Ricoeur. Su teoría del texto como crítica a los reduccionismos de Umberto Eco y Jacques Derrida. Buenos Aires, Prometeo.

- (2006). "El giro lingüístico como giro ontológico en la hermenéutica gadameriana”, en R. Alcalá y J. Reyes Escobar (comps.). Gadamer y las Humanidades, vol. 1: Estética, lenguaje y ontología. México, Facultad de Filosofía y Letras, Universidad Nacional Autónoma de México.

- (2013). “Diversidad lingüística: ¿diversidad acerca de qué?”, en C. Gende y E. Padilla (eds.). Diversidades en diálogo: interpretaciones, interpelaciones y realizaciones. Neuquén, Centro de Estudios en Filosofía de las Ciencias y Hermenéutica Filosófica del Comahue.

Ricoeur, Paul (2004). Sobre la traducción. Buenos Aires, Paidós.

Reynoso, Carlos (2014). Lenguaje y pensamiento. Tácticas y estrategias del relativismo lingüístico. Ciudad Autónoma de Buenos Aires, Sb.

SAPIR, Edward (2010). El lenguaje. Introducción al estudio del habla. México, Fondo de Cultura Económica. 